\title{
Facilitating evidence-informed practice
}

\author{
Article
}

Accepted Version

Flynn, N. (2019) Facilitating evidence-informed practice. Teacher Development, 23 (1). pp. 64-82. ISSN 1747-5120 doi: https://doi.org/10.1080/13664530.2018.1505649 Available at https://centaur.reading.ac.uk/72642/

It is advisable to refer to the publisher's version if you intend to cite from the work. See Guidance on citing.

To link to this article DOI: http://dx.doi.org/10.1080/13664530.2018.1505649

Publisher: Taylor \& Francis

All outputs in CentAUR are protected by Intellectual Property Rights law, including copyright law. Copyright and IPR is retained by the creators or other copyright holders. Terms and conditions for use of this material are defined in the End User Agreement.

\section{www.reading.ac.uk/centaur}

\section{CentAUR}

Central Archive at the University of Reading

Reading's research outputs online 


\section{Facilitating evidence-informed practice}

This article draws on the notion of communal constructivism to explore its potential to frame and facilitate the development of evidence-informed practice. The explicit aspiration to nurture a research-informed workforce is prominent in discourse across policy makers, educational researchers, and teacher professional groups in England; however, research evidence indicating how and why teachers might actually use research to inform their practice is limited. Furthermore the vision for research engagement of itself is not necessarily shared between researchers and practitioners. This study examines the relationships between research and practice when academics and professionals work together. Drawing on data from the co-construction of an online research-informed guide for the teaching of English as an additional language (EAL), analysis highlights the complexities inherent in translating research into practice for different stakeholders. Discussion argues for the recognition of communal constructivism as a pedagogy of learning that can build understanding between researchers and practitioners for how practice might become research-informed.

Key words: communal constructivism, research-informed teaching, knowledge mobilisation, English as an Additional Language (EAL)

\section{Introduction}

The aspiration that the teaching profession in England might be better informed about research and actively engaged with research has been prevalent in political and academic discourse in the UK for some years (BERA/RSA, 2014; DfE, 2014). Alongside this, commentary from academics has focussed on the concept of knowledge mobilisation (Ellwood, Thorpe, \& Coleman, 2013; Moss, 2013); a notion that captures how knowledge, in 
the form of empirical findings, might find its way from research to practice. There also exists some indication that both policy makers and teachers see online learning spaces as potential homes that might facilitate that journey (Dede, Ketelhut, Whitehouse, Breit, \& McCloskey, 2008; DfE, 2015). Furthermore it is recognised that particular environmental and relationship triggers can support effective researcher-practitioner relationships in realising the objective for research to inform practice (Dagenais et al., 2012; Peterson, 2016).

This article draws together the range of agenda presented above and explores how communal constructivism (Leask \& Younie, 2001; Mehan et al., 2001) might be employed to develop pedagogic theory that can drive forward a self-improving and research-engaged profession. It acknowledges the distinct place of technology common to earlier studies using communal constructivism but suggests that it contributes to both on and off-line activity that can inform practice. Discussion contributes to new thinking about evidence-informed practice in that it explores the possibilities for knowledge mobilisation between researchers and practitioners using a framework previously adopted in school settings between teachers and students. In doing so it attends to calls from existing studies for more understanding of the practical processes through which research might actively translate into practice (Dagenais et al., 2012; Peterson, 2016).

The commentary draws on data from a project in England involving an academic working with local authority specialist teacher advisors for EAL, teachers and teaching assistants in schools in order to create online research-informed guidance for teaching the rising cohort of children whose home language is not English in English schools (NALDIC, 2016). The focus on EAL (English as an Additional Language) learners in English schools was significant because funding and support for these pupils has reduced considerably in recent years despite the rise in their numbers in classrooms in the UK (Strand, Malmberg, \& Hall, 2015). The professional dissonance created between pupil demographic shift and under-provision of 
support means that there is an urgent need for teachers to have readily accessible support to inform their practice for EAL learners, but that support is unlikely to be available for them locally. Thus creation of online guidance was perceived as a route to facilitating teachers' continuing professional development (CPD) and to expediting the journey of research into practice for the teaching of EAL learners. In this way the research supporting discussion in this article gives a timely, real-world example of where finding pathways to evidenceinformed practice is both desirable and critical to professional development.

\section{Communal Constructivism}

The theory of communal constructivism was first introduced in 2001 as a way of framing the co-construction of new knowledge between teachers and pupils, and between pupils and their peers, when working with new technology (Mehan, Holmes, \& Tangney, 2001).It is described as an expansion of social constructivism in that learners build knowledge not only between themselves but for others and for future learners (p. 178). Knowledge construction through this medium is expressed as a communal, collaborative journey through which understanding is enriched by the process of joint exploration and discovery; and through which knowledge is more likely to survive and act as a fund for the building of understanding within and across learning communities. It is the creation of knowledge for future learning communities that is distinctive about the theory of communal constructivism, as is the sense that it is a form of social constructivism that specifically takes account of the affordances of technology (Leask \& Younie, 2001; Pountney \& Aspden, 2002).

Such different modes of knowledge construction and knowledge communities are exemplified in Girvan and Savage's (2010) study of students learning in a virtual 
environment which drew on communal constructivism as a pedagogy. For this study, student groups built a resource bank of e-books that were used by subsequent groups to facilitate their learning. In this way the students themselves- rather than their teachers - were responsible for knowledge generation that would inform peers coming to study after them. The process of teacher-student knowledge building was facilitated by collective responsibility for outputs that were agreed by all members of the community. For Girvan and Savage, communal constructivism was a manifestation of a socially constructive pedagogy which took account of the facilitative potential of new technology (p. 343).

Communal constructivism was also used as a tool for realising the potential in online learning platforms for teachers when employed as the framework for research by Younie and Leask (2013). These researchers built on their own earlier studies into how technology can advance the process of knowledge translation to inform teachers' practice, and through which they had developed an epistemology for communal constructivism as a process through which 'learners develop new knowledge and understanding (about pedagogic practice for the use of ICT) with and for each other.'(Leask \& Younie, 2001, p. 250). In their conclusions they observed that teachers were mostly motivated to use online learning platforms as peer to peer support mechanisms for collaborative peer learning and collaborative development and testing of practice. Thus, the process of collaborative construction of itself was the driver for knowledge development and a valued tool for teachers' continuing professional development (CPD).

It is notable that existing research exploring communal constructivism as an approach to learning assumes its partnership with new technology. This suggests that the notion belongs only in a virtual learning space but this perhaps limits its application to any wider discussion of how knowledge might be generated, translated, and mobilised by communities of 
practitioners, pupils, or researchers. Indeed, criticism of the presentation of communal constructivism as a 'theory of learning' takes issue with this assumption (Scrimshaw, 2001). Scrimshaw's critique is based not only on his view that communal constructivism has been defined rather narrowly when wedded with technology, but that it might be better defined as a practical and pedagogic theory rather than a theory that is something separate from social constructivism. It is, he observes, a pedagogic theory concerned with 'researching and understanding the ways in which good learning is brought about' (p. 136).

Scrimshaw's assertion is useful in building our understanding of the potential for communal constructivism to frame the processes involved in translating research into practice that might be shared in a knowledge-building community. Communal constructivism grows from a Vygotskyian understanding of the social construction of knowledge but identifies the practical systems through which knowledge mobilisation might be mediated. It goes further than suggestions of how knowledge translation might work by presenting a pedagogy through which it can work in practice

In essence, communal constructivism is the socially-mediated generation of new knowledge for current and future groups of learners. It requires the 'buy-in' of stakeholders to take collective responsibility for the creation of understanding that can move a community forward (Zhang, Scardamalia, Reeve, \& Messina, 2009). It suggests that the roles of teacher and student can be fluid (Girvan \& Savage, 2010); with this comes the possibility that it can also foster a necessary flexibility in the working relationships between researchers and practitioners (Van Kraayenoord, Honan, \& Moni, 2011).

Despite interest in the processes involved in translating research into practice from researchers, there is only a small body of research exploring communal constructivism as a platform for knowledge building, and none (with the exception of Younie \& Leask 2013) that 
applies it to activity between researchers and professionals. Furthermore there does not appear to be any research that has suggested its application might go beyond online learning spaces. Studies published so far construct new technology as the space in which communal constructivism takes place, but this does not take account of the ways in which community members will collaborate off-line or face to face as part of the way in way in which they interact with new technology. There is a need to test Scrimshaw's assertion that communal constructivism is a pedagogy of learning with a wider application than new technology. Before exploring how this pedagogic theory was applied in the present study, a discussion of the other agenda raised in the introduction is valuable.

\section{Teachers as evidence-informed and/or research-engaged}

The introduction to this article referred to research-informed practice and it was noted that there is not necessarily a shared understanding of what this might be. There has been ongoing interest from UK policy makers and academics in the belief that the teaching profession should become self-improving through research engagement in order to maximise pupil outcomes (BERA/RSA, 2014; DfE, 2014; Nelson \& O'Bierne, 2014). The debate is obscured at times by the shifting nature of what different stakeholders might mean by classroom practice being 'evidence-informed', or schools and teachers being 'researchengaged', and whether these are the same or different.

Fenstermacher's reflections $(1987,1994)$ on the problems of connecting research and practice are a reminder that this issue has long been under debate. On the one hand teachers see their practice as resting on their rich experiences and their professional understanding, and this is what they 'know', but on the other, academics wish to see teachers' understanding explicitly informed by research. For Fenstermacher this presents researchers with something of a dilemma because it highlights the fact that teachers' practical knowledge may be valued and 
perceived as somehow less important or significant than that which is theoretically or empirically grounded (1994, p. 10). Furthermore, the challenge for those wishing to support teachers in matching their practice with research findings is that research is frequently shaped for an audience of academics rather than practitioners; or when written for a teacher audience tends to focus on practice to the exclusion of theory.

Fenstermacher suggests that the route to a successful partnering of academics and practitioners comes with an 'educative approach' through 'practical argument' (1987). Practical argument involves discussion between academics and teachers that blends researchers' insights with teachers' practical knowledge. It facilitates the growth of teachers' understanding of where there is an empirical basis for their classroom choices, and academics' understanding of how research looks in practice. In this way, Fenstermacher argues,

"teachers are given access to new knowledge and understanding in ways that assist them to take possession of that knowledge, to work out its implications and its consequences for their own settings and contexts.” (p. 5)

Taking into account the discussion of communal constructivism in the previous section, it might be argued that this concept provides a facilitative framework for the realisation of practical argument. Communal constructivism as a pedagogic approach could potentially mediate the discussion between academic and practitioner as they work towards a shared interpretation of evidence-informed practice.

More recently, those who have attempted to unpack what evidence-informed practice might be, and how it is developed, have observed that it comes about when the practical nature of teachers' classroom lives are realised in the translation of knowledge from research (Behrstock, Drill, \& MIller, 2009; Cordingley, 2008). There is recognition that using 
teachers' continuing professional development (CPD) as the starting point from which to drive evidence-informed practice may be successful (Cordingley, 2008; Leask \& Younie, 2013), but this is dependent on researchers finding ways of making their findings accessible and readily transferable to practice for busy teachers whose energies are learner-focussed and 'hands-on'. Furthermore it depends on some understanding that there will be different kinds of research-engaged or research-informed practice depending on whether classroom practitioners are actively engaging in research or drawing on research to shape their deeper understanding of teaching and learning issues (Nutley, Jung, \& Walter, 2008). In brief, the roads to evidence-informed practice are likely to be messy and to involve compromise by the stakeholders involved.

Existing studies indicate that the nature of research-informed practice is complex and that the structures and strategies supporting the development of a self-improving profession must be multi-dimensional ; these dimensions relate to practitioners' existing attitudes to research; their perceptions that research is related to and relevant for their practice; and most importantly that research is developed communally between researchers and teachers in order to foster two-way dialogue that allows practitioners to feel instrumental in generating outcomes (Dagenais et al., 2012).

The ambition to translate research into practice brings with it a commitment to recognition that different stakeholders bring with them different sets of expectation and that relationships will necessarily need some negotiation (Ellwood, Thorpe, \& Coleman, 2013). Such differences are not necessarily acknowledged in different knowledge-sharing contexts and this of itself increases the opportunity for complexity in the process and the need for sensitivity to circumstances, experiences and expectations by all concerned (Higgins, 2015; Moss, 2013). Thus, recent discussion echoes Fenstermacher's earlier thinking, but we appear 
to be still some way from having an evidence basis which supports a shared understanding of how researchers' empirical knowledge can become teachers' practical knowledge.

Furthermore, we cannot assume that new technology of itself can serve this need.

Consultation with teachers in England about the ways in which the profession might become more research-engaged has suggested that the use of online guidance might be effective, but this also comes with a caution that such research must be rigorous and based on expert recommendation (DfE, 2014, 2015). In other words, web-based guidance for teachers must be both quality-assured and readily accessible if it is to foster a self-improving profession.

Arguably, it is in the teaching of children with EAL that the need to translate research into practice is needed most critically. This is because there is no recognised curriculum for EAL despite the rising numbers of children needing support for language acquisition in classrooms. Rather, it is assumed that teachers will adapt existing curriculum materials for monolinguals and that the teaching of EAL learners is more a teaching and learning than a curriculum concern (Leung, 2016). Thus, exploring how knowledge might be translated into practice in the study presented in this article brought with it the interesting but all the more complex dimension of the positioning of EAL within the National Curriculum in England (DfE, 2013). Moss (2013) rightly draws our attention to the need to examine the complex relationships taking place in mobilising knowledge for the profession, but different agents' relationship with the curriculum itself presents an additional layer of complexity (Author, 2013) .

As yet there exists a small body of research exploring the nature of communal constructivism within online learning spaces, but there is some suggestion that its potential might go beyond the confines of new technology. The study presented offers insights into how communal 
constructivism might be used as a vehicle for action between researchers and practitioners seeking pathways to evidence-informed practice.

\section{The Research Aims}

The research context for this project rested within and acknowledged the complex relationships between academics and practitioners seeking ways to match evidence with practice. The overarching aim was to co-construct an online guide for the teaching of EAL that synthesised theory and practice in a quality-assured, useable format for teachers needing ready access to research to enhance their understanding for and practice with the needs of their EAL learners. The research questions were:

1. What are the complexities inherent in relationships between academics and practitioners when co-constructing teacher-oriented research-informed guidance?

2. Can online materials support the research literacy and evidence-informed practice of teachers of EAL learners?

The expression 'research-literacy' was used to capture teachers' engagement with research in its widest sense in order to take account of the differing ways in which research-informed practice is conceptualised; that breadth includes how existing research influences teachers' practice and how teachers actively engage in classroom research.

\section{The Participants}

Those involved in this study were the research/writing team, the editorial team at (name of publisher) who were responsible for online construction and for quality control of the intended output, and participating teachers and learning support assistants from schools in a region of the south of England. The desire to publish translational research was the core 
purpose of the organisation supporting online publication, therefore the publishing platform was itself part of the communal approach to knowledge building.

The writers included a university-based teacher educator with a research profile and professional interest in the teaching and learning of EAL learners, and two expert professionals in EAL from a local authority team devoted to enhancing teachers' practice in supporting the attainment of children from ethnic/national minorities whose home language is not English. Thus the co-authors' first priorities both practically and as researchers were focussed on how to advance teachers' subject knowledge, and consequently their classroom practice, for the teaching of EAL learners. This differs from other researchers' investigations of communal constructivism where technology has been their core focus, and it begins to address Scrimshaw's assertion that communal constructivism is not just about online knowledge building communities.

The expert professionals from the ethnic minority support team identified schools likely to have suitable participants to work on the project: it was decided that working with schools and teachers who were relatively confident in their practice for EAL would afford a richer partnership for co-construction of the guide than working with those that were less experienced in managing linguistic diversity. A group of seven teachers and two learning support assistants with an EAL focus in their work were recruited from five schools representing all age-phases of education in England (Table 1). 
Table 1 Participants and their projects

\begin{tabular}{|c|c|c|c|}
\hline School type & $\begin{array}{l}\text { Participant (responsibilities } \\
\text { are cross-school) }\end{array}$ & $\begin{array}{l}\text { Year group of pupils } \\
\text { involved }\end{array}$ & Focussed use of EAL teaching guide \\
\hline \multirow{3}{*}{$\begin{array}{l}\text { School A: Primary school in } \\
\text { urban area with small but } \\
\text { rising population of EAL } \\
\text { learners. }\end{array}$} & $\begin{array}{l}\text { Classroom teacher with } \\
\text { responsibility for literacy }\end{array}$ & Year 1 (ages 5-6) & Developing EAL learners' phonological knowledge \\
\hline & $\begin{array}{l}\text { Classroom teacher with } \\
\text { responsibility for IT }\end{array}$ & Year 5 (ages $9-10)$ & $\begin{array}{l}\text { Developing language for writing with beginner EAL } \\
\text { learners }\end{array}$ \\
\hline & Newly qualified teacher & Reception (ages $4-5$ ) & $\begin{array}{l}\text { Creating opportunities for spoken interaction with EAL } \\
\text { learners }\end{array}$ \\
\hline $\begin{array}{l}\text { School B: Infant school in } \\
\text { urban area with } 20 \% \text { EAL } \\
\text { learners }\end{array}$ & $\begin{array}{l}\text { Senior teacher with } \\
\text { responsibility for additional } \\
\text { educational needs }\end{array}$ & Year 1 (ages 5-6) & Support for writing with EAL learners in Year 1 \\
\hline $\begin{array}{l}\text { School C: Infant school in } \\
\text { urban area with } 20 \% \text { EAL } \\
\text { learners }\end{array}$ & $\begin{array}{l}\text { Classroom teacher with } \\
\text { responsibility for literacy. }\end{array}$ & Year 2 (ages 6-7) & $\begin{array}{l}\text { Raising attainment in reading comprehension in an } \\
\text { advanced bilingual learner }\end{array}$ \\
\hline \multirow{2}{*}{$\begin{array}{l}\text { School D: Primary school in } \\
\text { urban area with } 25 \% \text { EAL } \\
\text { learners }\end{array}$} & $\begin{array}{l}\text { Senior teacher with } \\
\text { responsibility for literacy. }\end{array}$ & Year 6 (ages $10-11)$ & $\begin{array}{l}\text { Supporting advanced bilingual learners with grammar and } \\
\text { vocabulary knowledge }\end{array}$ \\
\hline & $\begin{array}{l}\text { Learning support assistant } \\
\text { (LSA), specialism of EAL }\end{array}$ & Years $\mathrm{R}-6$ (ages $4-11)$ & $\begin{array}{l}\text { Exploring resources for use by learning support assistants } \\
\text { working with EAL learners }\end{array}$ \\
\hline \multirow[t]{2}{*}{$\begin{array}{l}\text { School E: Secondary school } \\
\text { city with } 10 \% \text { EAL learners }\end{array}$} & $\begin{array}{l}\text { Teacher of foreign languages } \\
\text { with responsibility for EAL } \\
\text { learners }\end{array}$ & \multirow[t]{2}{*}{$\begin{array}{l}\text { Years } 7-9 \\
(\text { ages } 11-14)\end{array}$} & \multirow[t]{2}{*}{$\begin{array}{l}\text { Investigating strategies to develop reading word } \\
\text { recognition and comprehension in three EAL learners with } \\
\text { beginner proficiency in English }\end{array}$} \\
\hline & $\begin{array}{l}\text { Learning support assistant } \\
\text { (LSA), specialism of EAL. }\end{array}$ & & \\
\hline
\end{tabular}




\section{Research design and data collection methods}

The study took place through the academic year 2014-15 and involved an iterative approach of semi-structured interviews with all participants at three time points; action research in the participants' classrooms; and on-going drafting of the guide. In this way there was a sense in which all members of the team were positioned as collectively responsible for the planned content which would serve both the immediate needs of the classroom practitioners on the project team and the future needs of practitioners seeking evidence-informed guidance for teaching children with EAL.

In order to address the first research question the writing team undertook a review of existing research relating to EAL teaching and learning, drawing on their expert knowledge of the field and on their knowledge of working with practising teachers of EAL learners. Prior to drafting, the co-authors captured what professionals might want from the guide through semistructured interviews conducted in the autumn term. Questions focussed on which type of resources currently worked best for them and on what they would want from an online guide for EAL. Discussion included clarifying the intention to produce a guide that linked research findings with practice, and questions were framed with this as a core focus. Further interviews sought feedback in spring prior to use of the draft guide, and in summer before redrafting the guide following its use by the practitioners in their classrooms. Through this process it was intended that the guide was co-constructed by a research community, and would reflect the wishes of both the authors and the practitioners to provide researchinformed advice that was readily accessible and likely to inform classroom practice.

Data collection for the second research question involved the development of action research projects by the practitioners; these attended to the needs of individuals in their classes and drew on the online guide as the supporting mechanism to shape classroom interventions for 
EAL learners. The action research projects were devised by the teachers in partnership with the university-based researcher and all used a research planner adapted for use within this project. The choice of action research as the mechanism for exploring the guide's potential during its construction was made because action research is recognised as capacity-building through research activity that is participatory, collaborative and transformative (Koshy, 2010); thus it sits as a natural partner within a framework of communal constructivism, making it a valuable tool for exploring how knowledge is both developed and used. Using the spring and summer interview opportunities, data were also collected through questions that explored the teachers' perceptions of how the research-informed guide might have influenced their practice, and how far it had supported their use of action research to enhance their children's learning.

The approach taken to data analysis ensured that the research team took account of practitioner feedback in order that the ambition to co-construct the guide could be realised. Our iterative approach of Constructivist Grounded Theory, which is tempered by Charmaz' acknowledgement of the researchers' subjectivity in constructing meaning (Charmaz, 2014), was well-matched to a project which sought unity within potentially complex relationships and stakeholders' different starting points. Interview transcripts were coded using NVivo (QSR, 2010) at each stage of data collection, and emerging themes were shared, discussed and modified between members of the researcher-author team. This was challenging because coding revealed some disparity between what the authors valued and what the teachers valued, and this significant challenge is discussed below. However, the necessary navigation of this tension underscored the strength of Constructivist Grounded Theory as an approach to joint construction in that it demanded that the researchers engage with the alternative perspectives of the practitioners throughout the guide's composition. 
There were a variety of ways that schools involved themselves in the research: in some cases one teacher was involved, in others several teachers worked independently of each other, and in others a teacher worked with or independently from a learning support assistant whose working focus was on EAL learners. The complexity of researching how evidence-informed practice might come about is evident in these inter-school differences towards involvement in research: each will have had an implicit or explicit impact on how new knowledge could be built, explored and shared. However, the research team wanted to know how the guide might be used by future participants accessing it without the scrutinising gaze of its authors, and this required some freedom for the participants using the guide at the draft stage in order to assess realistically the guide's potential uptake and use. Such flexibility is identified as a strength in earlier studies into how practice can become evidence-informed (Dagenais et al., 2012)

\section{Findings}

\section{Relationships between academics and practitioners when co-constructing teacher- oriented research-informed guidance}

. The first draft of the guide combined the co-authors' expertise mediated by the practitioners' wishes expressed in the first interviews. Transcripts from the first round of interviews gathering practitioners' views about what they would want from such a guide were coded using the approach described above. In terms of attending to the first research question, substantial weighting in codes around practical and practice-related advice as being at the forefront of teachers' wishes for the online guide emerged from the data, and these themes impacted significantly on decisions taken by the authors (Figure 1). 
Figure 1: Weight of coding relating to teachers' wishes for MESHGuide content at pre-draft stage

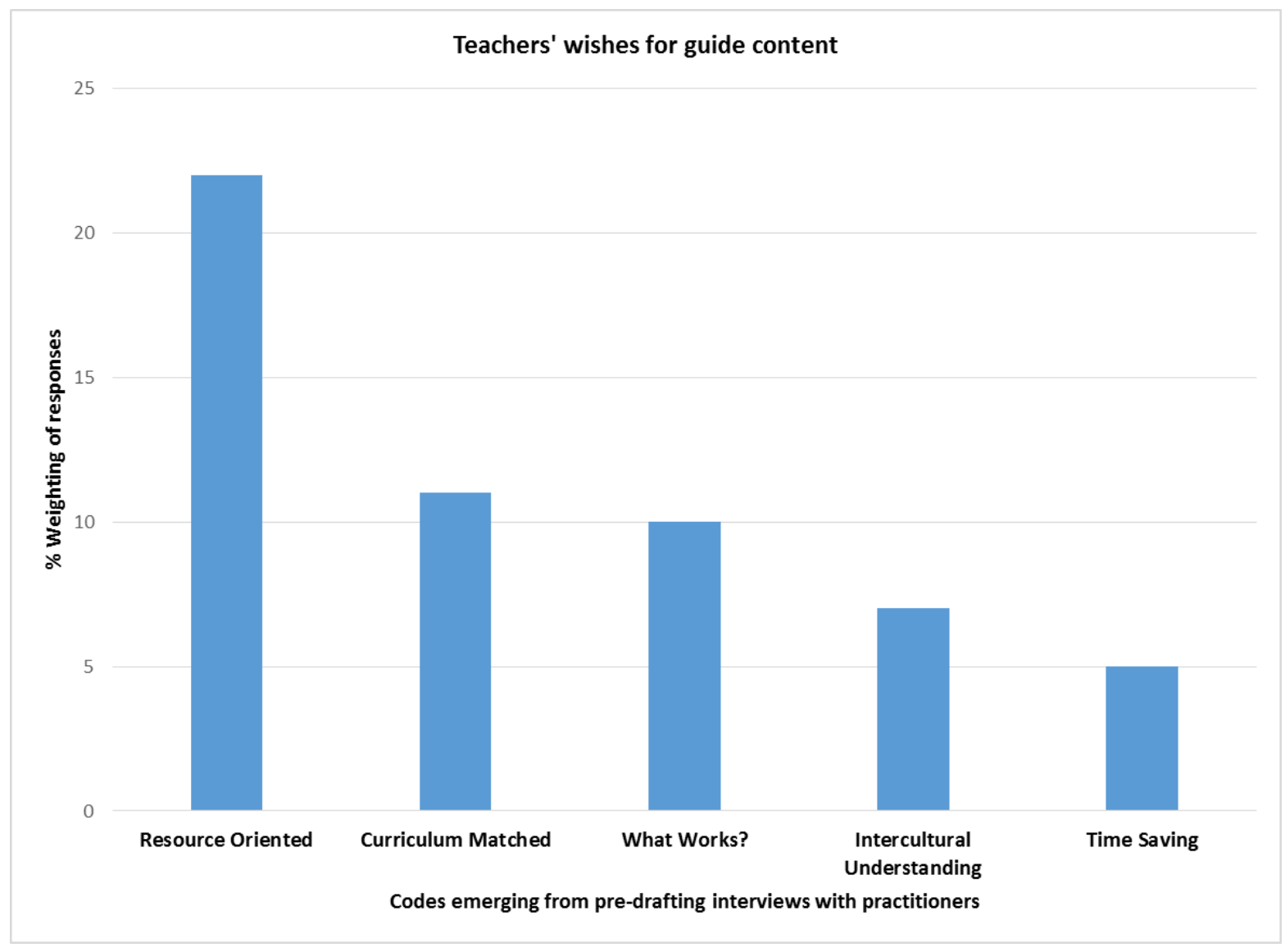

The responses illustrated teachers' desire for quick access to resources that were 'curriculummatched' and related to a 'what works' framework for their planning needs. This meant that any identified resources would need, for example, a match with the specific requirements for teaching phonics and for teaching spelling, grammar and punctuation which are assessed by high-stakes national tests in England. A Year 1 teacher from school A, concerned with 
supporting parents with the teaching of early reading through phonics, explained her needs in this way:

.....it would be phonics would be my big one....I've got these parents with this (language) background, they're struggling, but I don't have experience of having that language - what could I do to help them?

Also resources-focussed, the teacher and LSA from school E (a secondary school) wanted advice about reading scheme books that were for beginner English users but age-appropriate for their pupils with EAL who were 11 to 14 years old. Moreover, the wide range of subjects covered by the children in this age range meant that complex academic vocabulary was always problematic, and these practitioners wanted a bank of content-related terminology on which they could draw for pupils with varying levels of English proficiency.

This resource-oriented focus for the teachers was interesting for several reasons: firstly it illustrated that even when a project team enter into dialogue with practitioners about research-informed practice, it is framed in terms of easy-access practical solutions; and secondly that teachers working lives are governed by the external pressures of the curriculum and its assessment. In the first instance we are presented with a clear example of Fenstermacher's view of teachers' knowledge as practical, and it was crucial that the author team respected and embraced this. Particularly since the requests for resources of themselves indicated both teachers' commitment to the EAL learners and, importantly, their detailed understanding of effective pedagogy for EAL learners. Secondly, the teachers' interest in resources that matched curriculum expectations suggests that policy expectations will always influence what English practitioners will perceive as important in any guidance related to language and literacy, and that this may well be at odds with what researchers would want to prioritise (Author, 2013). 
The practitioners did acknowledge in our conversations that they felt that research should inform practice, but reference to research was synonymous in their discourse with what evidence would look like in practice. Most importantly they needed to know that any research was considered rigorous and indicated pedagogical approaches that worked in terms of raising attainment; again this was tied closely to teachers' professional habitus which is, consciously or unconsciously, governed by policy expectations (Author, 2013). Several participants mentioned that they would be willing to engage with research but it had to be written in accessible language and it had to be practically accessible (Behrstock et al., 2009). This sense of accessibility was also related to a desire that the guide be time-saving; that it saved the teacher from having to spend hours trying to discern what might be considered high-quality material from a standard internet search.

The year 5 teacher from school A described his need for quick access to ideas that an 'expert' had already decided would work; rather than him having to distinguish this for himself:

If you were to type in EAL, this whole bank just descends on you and I never know where to start with something like that. So... can you point me in the direction of something that will help with this: links, email addresses, resources?

A year 2 teacher in school $\mathrm{C}$ echoed this sense of not knowing where to start when presented with multiple possibilities in an internet search:

And it's knowing which ones are the best ones to do, because there's no idea about progression really.

Furthermore, she alluded to the tendency of internet resources to provide activities with no suggestion of which level of English proficiency they might be suitable for, or where to go next once the child had made good progress. 
The outcomes of this first round of interviews demanded of the authors that they consider their own preconceptions about what might be included in the guide's content. It also fostered debate among the authors about what might be non-negotiable and how authorial decisions be made palatable to the teachers as end-users. Thus, initial planning for the draft took account of differences between the co-authors' wishes as individuals within a group, of the differences between the wishes of the teachers and authors, and, necessarily, of how rigorous any research cited might be in terms of the views of other academics researching the same field.

Although the differences between stakeholders were not insoluble, they were certainly challenging (captured at Figure 2).

Figure 2: Tensions between stakeholders' wishes in the co-construction of the online guide for $E A L$

Practitioners
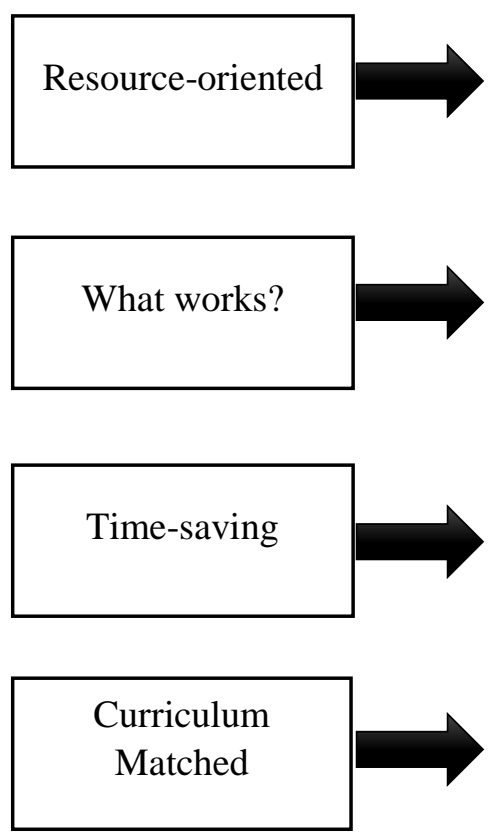

Researchers

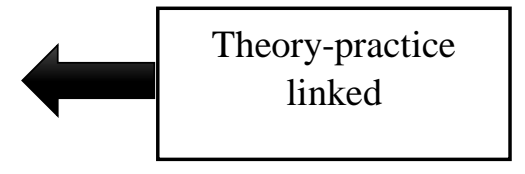

Whose 'expert recommendation'?

Succinct yet research-informed

Matched to English proficiency levels 
Looking at the different starting points for both thinking about and constructing the guide's content in Figure 2, it is apparent that there is not so much an opposition between them as a nuanced tension between what the practitioners wanted and what the authors considered important. The most obvious difference was the practitioners' wish for resources that worked and the authors' desire that any resource or practical guidance was explicitly supported by an empirical basis with which the reader engaged. The wish for things that match the "what works' agenda was also a tension for the authors as this, along with the request for 'expert recommendation', meant that the authors needed to agree between themselves on whose research to include and, of those, whose research could be summarised in a format accessible for teachers.

The brevity required by busy teachers was a major challenge, as was the desire for a match with the curriculum; as authors we respected the need for a curriculum match but were committed to a format that was structured around proficiency levels in English for EAL learners (Strand \& Demie, 2005), rather than with a format that was policy driven and therefore potentially time-limited. Moreover, it was our view that expanding the guide's content to include information supporting intercultural understanding, something requested by the teachers, would make the guide's focus too broad.

Addressing these differences as authors required considerable dialogue. We needed to come to some agreement about content that could genuinely inform practice. The conversations with teachers both about the guide and about their research projects took place face to face, off-line, but were as much a part of the co-construction of understanding about EAL teaching and learning as the use of the online guide. Thus we were taking part in a shared pedagogy of learning: a process through which we as authors were learning from each other how to share understanding about EAL learners while at the same time exploring the nature of that understanding through discourse with practitioners. The challenges in relationships between 
researchers and practitioners were best exemplified in this early dialogue, but they also arose in conversations focussed on the second research question and are thus also aired in the next section.

\section{The guide's impact on research literacy and evidence-informed practice}

Practitioners worked with their various projects using the EAL online guide as a basis for information during the second half of the spring term 2015, and during this time maintained email contact with the author team for advice and guidance. The outline plan for each project included references to research summaries within the guide that matched the small-scale interventions in which the teachers were engaging; in this way research was potentially informing the choice of activities they wanted to trial with their EAL learners. The practitioners then followed links within the guide which took them to well-regarded sites with practical advice for teachers such as those published by The British Council and England's National Association for Language Development in the Curriculum (NALDIC). The intention was that the teachers would explore how useful the guide was for their practice and thus give the author team feedback to make adaptations before the final draft.

In attending to the second research aim, interviews conducted with the practitioners after their trial of the guide focussed on what the users could identify as benefits of the content and the online platform, and on how far the guide had encouraged research literacy or evidenceinformed practice. While there remained a major focus in the teachers' conversations with us on how the guide had been useful for identifying practical resources and activities (resource/activity oriented) a range of other outcomes emerged from the coded interviews (Figure 3). 
Figure 3: Weight of coding relating to teachers' responses to benefits accrued from use of the online guide

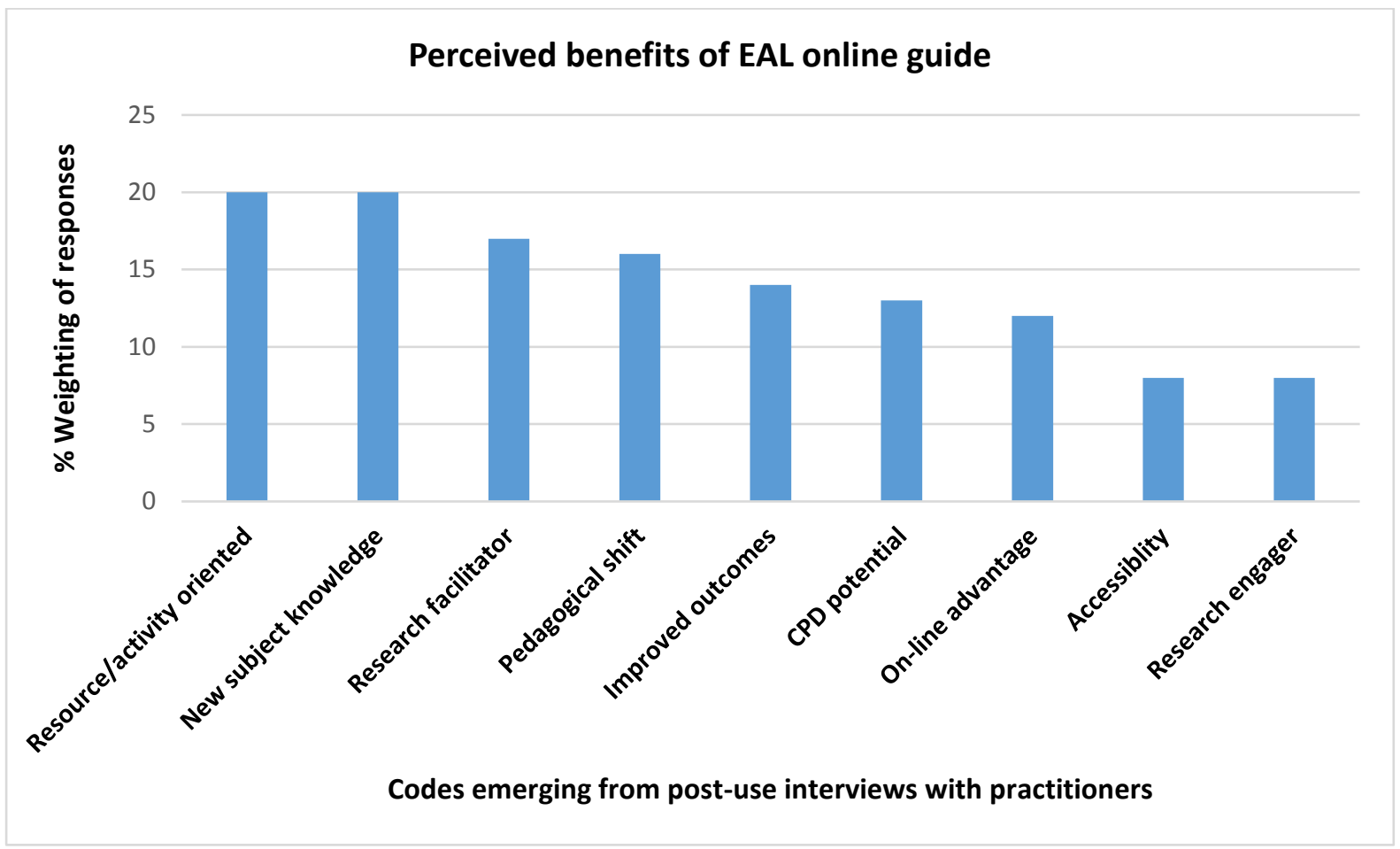

The acquisition of new subject knowledge for teaching EAL learners was among the most dominant of the themes in practitioners' responses, and this suggests that the guide did have the potential to enhance teachers' research literacy and evidence informed practice; albeit that this can only be a tentative outcome given the qualitative nature of the data collected. Practitioners from school D - a school with a very confident identity in terms of teaching EAL learners - noted that the guide confirmed and refreshed their existing subject knowledge. However all other participants commented on ways in which the guide had enhanced their subject knowledge.

The year 2 teacher from school $\mathrm{C}$ reflected on how the guide was 'particularly useful in terms of guidance for teaching reading, which I didn't realise I didn't know until I did... 'She had found both the summarised research around vocabulary development and the practical 
activities suggested for reading comprehension instructive for her practice with an advanced bilingual learner. Hers was an interesting observation because it calls into question how researchers might make decisions about what subject knowledge teachers need to know; if teachers themselves are not necessarily aware of what they do not know, they may not be receptive to the intentions of any vehicle - online or otherwise - for supporting evidenceinformed practice.

Closely matched to improvements in subject knowledge were participants' comments about how they had changed their teaching (pedagogical shift) and this was in response to improved outcomes in the pupils they had worked with as part of their action research projects. In some cases this led to a change in either their own or their schools' approaches to planning for teaching EAL learners. For example the teacher at school $\mathrm{C}$ decided that her team of colleagues working with the same age-range should add detail to their weekly plans which specifically identified what they would be doing to support their EAL learners:

To think before the planning to have an (EAL) intervention... we wouldn't have done it before, we wouldn't have thought that deeply or known where to go.

The Year 5 teacher in school A commented that the changes he had made to his teaching of writing for his new-to-English child had actually benefitted the writing of his less-able native-English speakers, and a range of strategies had become more firmly embedded in his practice as a result of information he had gleaned from the guide:

The use of visual prompts in class, including pictures, checklists, modelled writing, key vocabulary with definitions has proven helpful ... and this continues to be part of the classroom environment.

To a lesser extent, but still significant across the interviews, practitioners commented on the ways in which the guide might facilitate future practice in their schools. Most participants 
explained that they would be using the guide for the continuing professional development (CPD) of other staff in their settings; thus the ambition of communal constructivism was potentially realised in that the guide could become a learning tool for future users. As part of this there was consensus on the benefits of having guidance online and of the links to research we had made that were teacher-accessible. The experienced teacher of EAL children in school D noted how useful the guide would be for her own future practice with a new-toEnglish child arriving the following academic year:

In September I've got a child coming directly from Nepal. I've never taught a non-English speaker from the start, so I'll definitely have the guide on hand to support me.

The teacher and LSA in school E saw that the guide might be a valuable resource for teachers of particular subjects in their school, and that they as guide-users would become a CPD resource of themselves:

I can picture certain examples, perhaps the English department. They'll come to us and they'll say "What you do think we should do about this?" And I think having something like this (the EAL guide) available would (mean) we can advise them.

Furthermore teachers approved of the guide's capacity to evolve over time in responses to teacher feedback, and they liked the incorporation of their own research as case studies included in the guide's content. The conversations about CPD-potential were forwardlooking in ways that suggested the choice of communal construction of the guide in a community of learners had created something of value for future practitioners.

Although the potential around subject knowledge development and CPD opportunities were positive outcomes from the collaboration, it was difficult to discern whether the growth in subject knowledge and the sense of pedagogical shift could really be described as evidence- 
informed practice. Coding revealed that the guide had clearly supported teachers' own action research (research facilitator) with their individual children, but there was less evidence that it had encouraged them to read more research in order to inform their practice (research engager). The examples above clearly evidence teachers' adoption of practical solutions for their children's needs, but in conversation this was related back to summaries of research rather than to particular empirical studies. This suggests that collaborative research employing 'practical argument' might engage teachers with empirical evidence to some extent, but perhaps leaves open to question whether evidence informs practice in the direct way that we as researchers might desire.

\section{Discussion}

The findings relating to the two research questions were to some extent intertwined. The relationships between the researchers and the practitioners impacted on whether the guide had the potential to support evidence-informed practice, while the ways in which the teachers used the guide had implications for future researcher-practitioner relationships. For this reason, the upcoming discussion of the significance of the findings presented above sometimes conflates the two.

With regard to researcher-practitioner relationships, there was a constant tension between the researchers' desire to foreground empirical findings and the teachers' desire to have practical solutions. However, the commitment to collaborative knowledge building from the outset tempered discussion and decisions so that the guide was much more practice-oriented than we might have written without teachers' insights. In some ways this was the most powerful and transformative outcome of the project for the co-authors. 
Our navigation of the differences in stakeholder expectations throughout the project also indicated a need to define more carefully the ambition that teachers develop evidenceinformed practice; there was still a sense that, in common with other research, we were still finding out what evidence-informed practice might be. Throughout this study stakeholders' ambitions for the outcome grew from very different starting points for the academic, for the professional experts, and for the school-based participants (Moss, 2013). Remaining open to these differences and acknowledging them grew explicitly from the commitment to communal constructivism as a process of learning from each other. This supports the view that researcher - practitioner investigations need to be partnerships of equals - albeit messy partnerships - and that setting up research design with the express intention of supporting this type of enquiry commits all stakeholders to its success.

It was also important that the researchers took account of the differing ways in which schools as potential knowledge building communities came to the research. In some cases participants engaged wholesale both with the research informing the design of their action research projects and with the action research process itself. In others participants were less confident to engage with the empirical basis but fully engaged with the practical outcomes of their interventions with the children. Future research involving different professional communities in this way would need to control for the varied responses schools have to research engagement; although this might of itself negate the value of allowing for differences in order to explore fully how it is possible to co-construct meaning. Particularly if we consider that previous research has identified the strength in allowing practitioner research to be responsive to local needs (Behrstock et al., 2009)

Gathering evidence that an online guide might foster teachers' research literacy or evidenceinformed practice was challenging because of the noted ill-defined nature of each of these constructs. While there was a generally positive response to the value of the guide, and its 
flexibility as an online learning tool, it was difficult from the interview data to ascertain whether there was a growth in participants' engagement in reading research to inform their own practice. This was in part related to users being unable to access research beyond the summarised commentary the authors created for them, but also because of their wish to seek practical help as quickly as possible; thus the links to high quality resource-related websites were by far the most visited parts of the guide.

Significantly, practitioners tended towards a conflation of research - whether reading research or engaging in research - with professional development, and this was evident in their universal recommendation of the guide for CPD. If professional development and research literacy are conceived as synonymous by practitioners then findings from this study support observations from other researchers that the development of a research-engaged profession should focus on professional development opportunities as starting points (Cordingley, 2008; Leask \& Younie, 2013). It also underscores the already acknowledged fact that teachers are practical professionals and that any research-engagement will need to chime with this practical identity (Behrstock et al., 2009; Dagenais et al., 2012). There is perhaps a sense in which teachers are naturally researchers if academics can value professional development as a form of research.

Indeed one of the strengths identified was that the ambition to co-construct the EAL guide facilitated participants' capacity to shape their own research agenda (Behrstock et al., 2009). They could operate within their own contexts in order to design classroom interventions that were personalised to their pupils and adapted to their localised working practices; in this way their own construction of knowledge was very clearly happening both on and offline, thus going beyond what has been explored of communal constructivism in earlier research. 
Arguably, providing practitioners with a freedom to design their own interventions at a time when there is increasing interest in the type of rigorous research paradigm identified in randomised control trials is unhelpful; but conversely we might hope that research-engaged professionals will become sufficiently research-literate in order that they can select research approaches to best suit their research purposes, and that offering choice is an asset. Moreover, in analysis of the end of project interviews in particular, the coding highlighted the difficulty of disambiguating teachers' understanding of practice from their understanding of research. On teacher training courses these differences are made explicit for trainees, but for experienced practitioners the lines are blurred and this is another feature of practice that complicates the whole notion of evidence-informed practice.

A clearer outcome of the communal construction of the EAL guide was the development of subject knowledge in several different ways. The co-authors' subject knowledge for the teaching and learning of EAL pupils grew in terms of an enhanced understanding of what is important as a knowledge base for teachers; it also grew through the necessary dialogue around the writing of the guide. For the practitioners, subject knowledge developed by virtue of engaging in the research process using the guide's content as a reference point for information. However, several commented on finding out things that they were unaware of before; and, furthermore, that they did not recognise previously as a gap in their knowledge: this dichotomy for researchers who wish to advance teachers' subject knowledge for teaching EAL is a particularly complex one.

It could be the case that teachers 'didn't know what they didn't know' because we were working to improve practitioner subject knowledge for teaching EAL and this is commonly an area in which practitioners lack detailed subject knowledge. Nevertheless, the finding suggests that if researchers are to successfully translate findings into practice they need to take account of the fact that practitioners will only seek knowledge if they are aware that this 
new knowledge has value for them. Thus, further examination is needed of what sorts of knowledge the profession has, or does not have, and furthermore whether they either want or need such knowledge. This requires that academics engage with and embrace the different ways of knowing that teachers exhibit because these are not congruent with academic knowledge (Fenstermacher, 1994). It also brings to mind Fenstermacher's 'educative approach' to teacher-researcher relationships (1987) and suggests that communal constructivism is potentially a medium for the kind of 'practical argument' that can allow the teacher to see through the researchers' eyes and vice-versa.

It became clear during the study that a pedagogy of learning was supporting the development of new understanding both on and offline. The value of online guidance was universally referred to by the participants, but equally they valued the opportunity to put the guidance into practice and discuss the outcomes in real time with the researcher. This perhaps indicates that evidence-informed practice is best sought through a mixed economy of face to face and virtual interaction with the empirical basis supporting effective teaching; but more research is needed into the different ways in which this might emerge in different arena and with different sets of subject knowledge. In areas such as the teaching of EAL, where support is limited both on and offline, there is a place for online guidance; but this study suggests quite strongly that of itself it is only part of a supporting structure. Furthermore it suggests that online learning potential grows from real-world needs discussed in real-world settings, and this demonstrates that the benefits of a communally constructive approach are about more than the affordances of new technology.

\section{Conclusion}


This study set out with the intention of throwing light on the ways in which researchers and practitioners can work collaboratively in order to facilitate evidence-informed practice for the teaching of children with EAL through the co-creation of online guidance. While the data are limited they draw together existing research exploring the strands of thinking involved in an ambition to foster teachers' research literacy and they go some way to explaining and exploring the complexities and nuances of difference between stakeholders in educational research . The outcomes suggest that there is a need not just for researchers to find ways of mobilising knowledge by making their own research accessible, but that the process of translation of research into practice must include practitioners if it is to be successful. Despite the considerable effort involved in negotiating researcher-practitioner partnerships, the author team were well aware that the final draft was much more likely to be used by teachers than one written without teacher collaboration.

More practical investigations of the processes involved in translating knowledge into practice are needed in order that we come to an understanding of the different ways in which researchers and practitioners define and engage in evidence-informed practice. Without greater consensus between the different communities involved in research in either virtual or real -world learning spaces it is difficult to see how the current desire to develop teachers' research literacy can move forward. Navigating professional - researcher differences is essential if academics are to avoid being stymied in their attempts to make available to practitioners the research that can inform practice. Framing research as communally constructive offers a way forward.

Word count 8473

References 
Behrstock, E., Drill, K., \& Miller, S. (2009). Is the Supply in Demand? Exploring How, When and Why Teachers Use Research. Learning Point Associates(March 2009), 121.

BERA/RSA. (2014). Research And The Teaching Profession: Building The Capacity For A Self-Improving Education System, Final Report Of The BERA-RSA Inquiry Into The Role Of Research In Teacher Education (BERA Ed.). London: BERA/RSA.

Charmaz, K. (2014). Constructing Grounded Theory (2nd ed.). London: Sage.

Cordingley, P. (2008). Research and evidence-informed practice: focussing on practice and practitioners. Cambridge Journal of Education, 38(1), 37-52.

Dagenais, C., Lysenko, L., Abrami, P. C., Bernard, R. M., Ramde, J., \& Janosz, M. (2012). Use of research-based information by school-based practitioners and determinants of use: a review of empirical research Evidence and Policy: A Journal of Research, Debate and Practice, 8(3), 285-309.

DfE. (2013). National Curriculum in England: English programmes of study: www.education.gov.uk/nationalcurriculum.

DfE. (2014). A World Class Teaching Profession: Government Consultation. Sheffield: Department for Education.

DfE. (2015). A World Class Teaching Profession: Government Response (D. f. Education Ed.). Sheffield: Department for Education.

Ellwood, P., Thorpe, R., \& Coleman, C. (2013). A model for knowledge mobilisation and implications for the education of social researchers. Contemporary Social Science Journal, 8(3), 191-206.

Fenstermacher, G. (1987). On understanding the connections between classroom research and teacher change. Theory into practice, 26(1), 3-7. 
Fenstermacher, G. (1994). The Knower and the Known: The Nature of Knowledge in Research on Teaching. Review of Research in Education, 20, 3 - 56.

Author (2013)

Girvan, C., \& Savage, T. (2010). Identifying an appropriate pedagogy for virtual worlds: A Communal Constructivism case study. Computers and Education, 55, 342-349.

Higgins, S. (2015). An Overview of Recent Reviews about Evidence-Based Teaching. Paper presented at the British Educational Research Association Annual Conference, Belfast.

Koshy, V. (2010). Action Research for Improving Educational Practice (2nd ed.). London: Sage.

Leask, M., \& Younie, S. (2001). Communal constructivist theory: Information and communications technology pedagogy and internationalisation of the curriculum. Journal of Information Technology for Teacher Education, 10(1-2), 117-134.

Leask, M., \& Younie, S. (2013). National models for continuing professional development: the challenges of twenty-first-century knowledge management. Professional Development in Education, 39(2), 273-287.

Leung, C. (2016). English as an additional language - a genealogy of language-in-education policies and reflections on research trajectories. Language and Education, 30(2), 158174.

Mehan, S., Holmes, B., \& Tangney, B. (2001). Who wants to be a teacher? An exploration of the theory of communal constructivism at the chalk face. Teacher Development, 5(2), 177-190.

Moss, G. (2013). Research, policy and knowledge flows in education: What counts in knowledge mobilisation? Contemporary Social Science Journal, 8(3), 237-248. 
NALDIC. (2016). EAL pupils 1997 - 2013. Retrieved from http://www.naldic.org.uk/research-and-information/eal-statistics/eal-pupils/

Nelson, J., \& O'Bierne, C. (2014). Using evidence in the classroom: What works and why. Slough: NFER.

Nutley, S., Jung, T., \& Walter, I. (2008). The many forms of research-informed practice: a framework for mapping diversity. Cambridge Journal of Education, 38(1), 53 - 71.

Pountney, R., \& Aspden, L. (2002). Community and Constructivism: Implicit Pedagogical Models in Virtual Learning. Paper presented at the World Conference on E-Learning in Corporate, Government, Healthcare, and Higher Education, Montreal, Canada.

QSR, I. (2010). NVivo 9: http://www.qsrinternational.com.

Scrimshaw, P. (2001). Communal constructivist theory: a response to Leask \& Younie. Journal of Information Technology for Teacher Education 10(1-2), 135-141.

Strand, S., \& Demie, F. (2005). English language acquisition and educational attainment at the end of primary school. Educational Studies, 31(3), 275-291.

Van Kraayenoord, C. E., Honan, E., \& Moni, K. B. (2011). Negotiating knowledge in a researcher and teacher collaborative research partnership. Teacher Development, 15(4), 403-420.

Zhang, J., Scardamalia, M., Reeve, R., \& Messina, R. (2009). Designs for Collective, Cognitive Responsibility in Knowledge-Building Communities. Journal of the Learning Sciences, 18(1), 7 - 44. 